\title{
RELAÇÃO OBSERVADA PELOS MORADORES DA CIDADE DE CURITIBA-PR ENTRE A FAUNA E ÁRVORES FRUTÍFERAS.
}

\author{
Ariádina Reis de Almeida ${ }^{1}$, Leila Maria Zem², Daniela Biondi ${ }^{3}$
}

(recebido em 11.11.2008 e aceito para publicação em 19.03.2008)

\begin{abstract}
RESUMO
Esta pesquisa teve como objetivo obter informações sobre a relação dos moradores com as árvores e os animais presentes nas ruas de Curitiba. Para a sua realização, foram selecionadas cinco ruas que estavam arborizadas com espécies frutíferas. Foram amostradas as seguintes espécies: goiabeira (Psidium guajava L.), pitangueira (Eugenia uniflora L.), cerejeira-do-japão (Prunus serrulata Lindl.), guabirobeira (Campomanesia xanthocarpa O. Berg.), araçazeiro (Psidium cattleyanum Sabine), tarumã (Vitex montevidensis Cham.) e jerivá (Syagrus romanzoffiana (Cham.) Glassman.). Através de um questionário estruturado foram feitas entrevistas aos moradores contendo questões referentes à arborização das ruas e a fauna associada. Para cada morador entrevistado foi dado um folder contendo informações sobre as árvores frutíferas plantadas em Curitiba e a fauna correlata. De todos os registros realizados, $85 \%$ revelaram que os moradores tinham conhecimento sobre a árvore plantada em frente de suas casas; $55 \%$ das árvores foram plantadas pela Prefeitura; 85\% dos entrevistados indicaram corretamente a espécie frutífera perguntada e $61 \%$ responderam já ter visto alguma ave na árvore em frente a sua casa. Os resultados indicaram que os entrevistados parecem relacionar-se bem com a arborização viária, pois muitas vezes conhecem o histórico das árvores plantadas em frente às suas casas e acompanham o desenvolvimento das mesmas.
\end{abstract}

PALAVRAS-CHAVE: arborização urbana, fauna urbana, árvores frutíferas, percepção.

\footnotetext{
${ }^{1}$ Bióloga, Colaboradora do Museu de História Natural, Departamento de Zoológico, Prefeitura Municipal de Curitiba. ariadina almeida@yahoo.com.br

${ }^{2}$ Bióloga, Setor de Educação Ambiental da Prefeitura Municipal de Curitiba. leilamariazem@yahoo.com.br

${ }^{3}$ Engenheira Florestal, MSc. Dra. Engenharia Florestal, Departamento de Ciências Florestais, Universidade Federal do Paraná. Bolsista do CNPq - Departamento de Ciências Florestais, Rua Lotário Meissner, nº 900, Jardim Botânico - Curitiba, PR. CEP: 80.210-170. E-mail: dbiondi@ufpr.br
} 


\title{
THE PERCEPTION OF THE RELATIONSHIP BETWEEN FRUIT TREES AND FAUNA BY RESIDENTS OF CURITIBA CITY, PARANÁ STATE.
}

\begin{abstract}
This research aimed to collect information on the perception of the relationship between street fruit trees and the fauna by residents of Curitiba City, PR. This was accomplished in five streets planted with the following fruit tree species: guava (Psidium guajava L.), Surinam cherry (Eugenia uniflora L.), Japanese flowering cherry (Prunus serrulata Lindl.), guabirobeira (Campomanesia xanthocarpa O. Berg.), cattley guava (Psidium cattleyanum Sabine), tarumã (Vitex montevidensis Cham.), and queen palm (Syagrus romanzoffiana (Cham.) Glassman.). The residents were interviewed with a structured questionnaire on the street trees and the associated fauna. Each interviewee received a folder with information on the fruit trees planted in Curitiba streets and the associated fauna. The results showed that $85 \%$ of the residents knew the street trees planted in front of their houses, $55 \%$ of the trees were planted by the city hall, $85 \%$ of the interviewees indicated the asked fruit tree species correctly, and $61 \%$ reported to have seen some bird on the trees in front of their houses. The results indicate that the interviewees relate well with Curitiba's urban street trees, often knowing the history of the trees planted in front of their houses and following their development.
\end{abstract}

KEY WORDS: urban forest, urban fauna, fruit trees, perception. 


\section{INTRODUÇÃO}

Atualmente as questões ambientais têm sido cada vez mais relevantes por estarem comprometendo a sobrevivência do homem no planeta. As mudanças climáticas, poluição hídrica, edáfica e do ar, diminuição dos recursos materiais, acúmulo de resíduos sólidos, e outras, são as principais causas deste comprometimento.

A progressiva migração da população para áreas urbanas, seu crescimento e organização, têm efeitos intensivos com alterações profundas nos sistemas naturais, na paisagem das cidades e nos padrões de qualidade ambiental no meio urbano.

Os problemas das cidades modernas não são diferentes daqueles que afetam as cidades antigas, a não ser quanto ao grau, à toxicidade e a persistência dos contaminantes, e a extensão da terra que está agora urbanizada. Muitas cidades sofrem com problemas de poluição atmosférica, sonora e visual, que prejudicam o bem-estar das pessoas que nelas vivem. À medida que as cidades crescem em tamanho e densidade, as mudanças que produzem no ar, no solo, na água e na vida, agravam os problemas ambientais que afetam o bem-estar de cada morador (SPIRN, 1995).

Com o passar do tempo, o homem se distanciou do convívio direto com a natureza e passou a viver em cidades, mas a busca por essa necessidade biológica sempre existiu. Segundo Spirn (1995), isso pode ser verificado através de milênios, em jardins, parques, subúrbios e cidades-jardins. A arborização de vias públicas ou urbana é um exemplo disso. Segundo Dantas e Souza (2004) ela tem a finalidade de trazer para as cidades um pouco do ambiente natural, sendo um indicador de qualidade de vida.

Inúmeros são os benefícios proporcionados pelas árvores encontradas nas áreas públicas. Elas exercem função ambiental, psicológica e ecológica importante para o ambiente urbano e a população humana (RODRIGUES, et al., 2002; DANTAS e SOUZA, 2004; BIONDI e ALTHAUS, 2005; ROPPA et al., 2007).

Além das funções que afetam diretamente a vida do homem, a arborização urbana é fundamental sob o ponto de vista ecológico. Através dela, pode-se salvaguardar a identidade biológica da região, preservando as espécies vegetais que ocorrem em cada município. São elas também que oferecem abrigo e alimentação à fauna local e dessa forma protegem o ecossistema como um todo (DANTAS e SOUZA, 2004).

Outro aspecto muito importante relacionado com as árvores de rua é seu préstimo como corredor ecológico, interligando as áreas livres vegetadas da cidade, como praças e parques (RODRIGUES et al., 2002). Esse fator é imprescindível para a fauna urbana, pois o 
tamanho do hábitat é muitas vezes o fator limitante para a sobrevivência desses nas cidades (SPIRN, 1995).

Tanto a fauna como a flora urbana enfrentam pressões diárias e constantes. A poluição do ar, da água e concorrência com o homem por recursos, são fatores limitantes que acabam selecionando as espécies mais resistentes e versáteis na utilização de recursos essenciais a sua sobrevivência (SPIRN, 1995).

As cidades contêm fragmentos de hábitat natural e podem ser manejadas e desenhadas para otimizar a abundância de vida silvestre. Assim, fragmentos de hábitat natural podem funcionar como refúgio para espécies de plantas e animais e promover oportunidade para evitar a extinção de espécies ameaçadas (FRANCHIN et al., 2004).

A forma da cidade limita não só a abundância como a diversidade da vida selvagem. Segundo Spirn (1995), a cidade fornece grande número de novos habitats, incluindo edifícios, parques, quintais, corredores de tráfego e depósito de lixo. Porém, pequenos parques urbanos oferecem pouca segurança contra predadores e uma pequena quantidade de plantas como fonte de alimento. Além disso, os jardins e quintais particulares representam um espaço limitado. Essa fragmentação de habitats elimina a maioria da vida selvagem que migra pelo solo ou sobre ele. Embora as aves possam voar de uma área verde a outra, elas só irão deslocar-se se as ilhas de habitat atrativas forem grandes e interligadas.

A arborização de ruas e avenidas no Brasil é uma prática nova em comparação com os países europeus (DANTAS e SOUZA, 2004; SPIRN, 1995). Em Curitiba esse processo começou no século XIX. Inicialmente o objetivo estava relacionado à salubridade pública (OBA, 1998). Nessa época foram plantadas várias espécies, entre elas, árvores exóticas e nativas, porém, depois de algum tempo surgiu a preocupação de arborizar com espécies nativas (BIONDI e ALTHAUS, 2005). A partir de 1990, Curitiba começou a traçar sua face "ecológica", realizando o reflorestamento de pedreiras desativadas ou de fundos de vale inaproveitáveis para expansões urbanísticas. Hoje é considerada uma das metrópoles brasileiras mais bem planejadas e com ótima qualidade de vida, contando com extensas áreas verdes e grande diversidade de fauna e flora (Curitiba, 2008).

Quanto maior a quantidade de árvores frutíferas no ambiente urbano, maior é a disponibilidade de micro ambientes ofertados à vida silvestre. Porém, não são somente as frutíferas que oferecem subsídios para a fixação e equilíbrio da fauna silvestre urbana, outras plantas não-frutíferas podem ter a flor como alimento (MENDONÇA e ANJOS, 2005; 2006), como é o caso da Caliandra (Calliandra sp.) e o Hibisco (Hibiscus sp.) (OLIVEIRA, 1990). 
A arborização urbana com plantas frutíferas é praticamente inexistente nas cidades brasileiras, havendo poucos trabalhos realizados e publicados no mundo (MANICA, 1997). Segundo Andrade (2002), em 10\% dos bairros de Campos do Jordão-SP inventariados, apenas uma árvore frutífera foi encontrada. Em Piracicaba-SP o número de espécies que compõem a arborização do município é de 6,14\% (MICHI e COUTO, 1996) e em Sete de Setembro-RS, apresenta 12\% (COLETTO et al., 2008).

Diversas espécies de animais que vivem e ocupam o ambiente urbano. Nas áreas verdes de Curitiba podem-se encontrar mamíferos como: gambá (Didelphis sp.), esquilo (Sciurus sp.), preá (Cavea sp.), ouriço (Sphiggurus sp.), capivara (Hydrochaeris hydrochaeris), vários marsupiais e roedores silvestres de pequeno porte e, segundo Miretzki (1996), 12 espécies de morcegos. Além de mamíferos, um grande número de aves faz parte dessa biodiversidade animal que se beneficia de alimento e abrigos disponíveis na cidade.

A principal fonte de alimentação para a fauna urbana está na vegetação. É através dela que mamíferos, aves, répteis e anfíbios adquirem os frutos, as flores, o néctar e os insetos. Neste contexto, as árvores frutíferas plantadas ou cultivadas nas cidades são de grande valia para manter o equilíbrio e a harmonia do ecossistema urbano.

A fim de evidenciar a importância das árvores frutíferas para a existência e a manutenção da fauna urbana é que esta pesquisa, de caráter exploratório, teve como objetivo obter informações sobre a relação dos moradores com as árvores e os animais presentes nas ruas de Curitiba.

\section{MATERIAL E MÉTODO}

\section{Descrição do local}

Esta pesquisa foi realizada na cidade de Curitiba, capital do Paraná, localizada no primeiro planalto paranaense, a $25^{\circ} 25^{\prime} 40^{\prime \prime}$ de latitude sul e $49^{\circ} 16^{\prime} 23^{\prime \prime}$ de longitude oeste (MAACK, 1981). Atualmente, segundo dados do censo de 2007, a cidade possui uma população de 1.797.408 habitantes, distribuídos em uma área de 434,967 km² (IBGE, 2008).

Curitiba está situada no Primeiro Planalto Paranaense e possui topografia ondulada de colinas suavemente arredondadas, caracterizada por uma série de terraços escalonados dispostos em intervalos altimétricos. O ponto mais elevado está ao norte do município, correspondendo à cota de 1.021,00 m de altitude, e o ponto mais baixo ao sul, na cota de 864,90m, na cabeceira do rio Iguaçu (IPPUC, 2004). 
O município de Curitiba é composto de 75 bairros, divididos em nove regionais administrativas, que são: Bairro Novo, Boa Vista, Boqueirão, Cajuru, ClC, Matriz, Pinheirinho, Portão e Santa Felicidade (IPPUC, 2006).

O total de área verde disponível na cidade, segundo a Secretaria Municipal de Meio Ambiente (SMMA) de 2000, é de 77.901.198,20 $\mathrm{m}^{2}$, e o índice de cobertura vegetal por habitante, de 49,08 $\mathrm{m}^{2}$. Segundo levantamento da mesma Secretaria, para o mesmo ano, o município conta com 30 unidades de parques e bosques, 11 núcleos ambientais, cinco jardins ambientais, 54 largos, 15 eixos de animação, 393 praças e 330 jardinetes (IPPUC, 2004). Segundo a GERÊNCIA (2006), Curitiba possui aproximadamente 300 mil árvores plantadas em suas vias públicas.

\section{Procedimento metodológico}

Como os plantios de árvores frutíferas nas vias públicas não foram realizados de forma sistemática e também muito deles foram realizados informalmente por moradores, foi impossível se obter previamente a quantidade e as espécies existentes na cidade de Curitiba. Esta informação só poderia ser obtida através de um censo, isto é, um inventário total das árvores frutíferas plantadas em calçadas. Por esta razão foram amostrados poucos exemplares de árvores em cinco ruas de diferentes bairros, por indicação da Prefeitura Municipal de Curitiba - Departamento de Produção Vegetal (Figura 1).

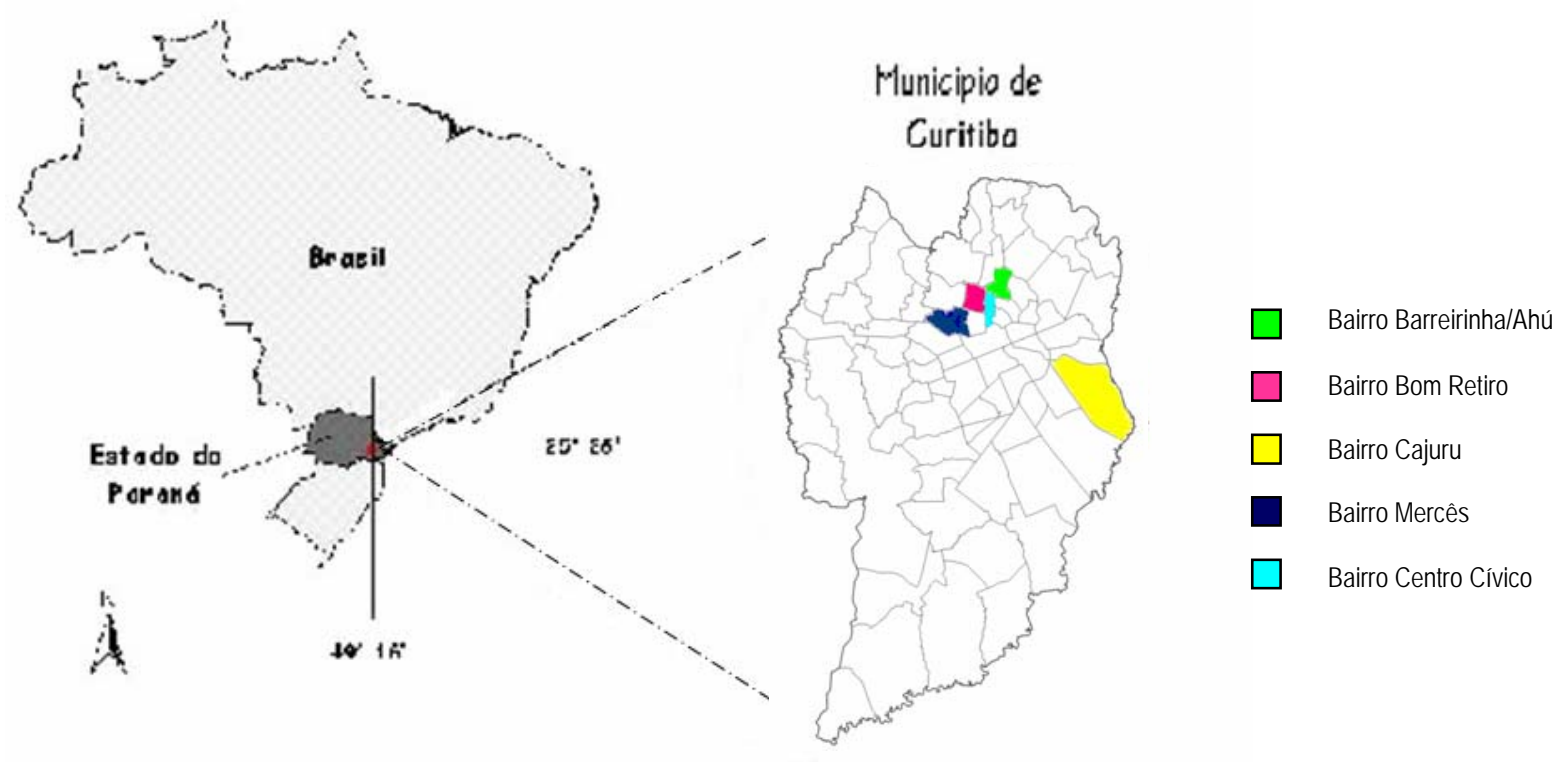

Figura 1. Mapa com a localização dos bairros amostrados em Curitiba 
A amostragem de árvores para a realização desta pesquisa foi pequena porque foi priorizada a diversidade de espécies frutíferas (7 espécies). Supõe-se que com isto, se aumentaria a oportunidade de conhecer também a diversidade da fauna com as árvores frutíferas. Foram selecionadas as seguintes espécies frutíferas: Cerejeirado-japão (Prunus serrulata Lindl.), Guabirobeira (Campomanesia xanthocarpa O. Berg.), Jerivá (Syagrus romanzoffiana (Cham.) Glassman.), Araçazeiro (Psidium cattleyanum Sabine), Goiabeira (Psidium guajava L.), Pitangueira (Eugenia uniflora L.) e Tarumã (Vitex montevidensis Cham.) (Tabela 1).

Tabela 1. Seleção das ruas e espécies frutíferas visitadas em Curitiba, 2008.

\begin{tabular}{ll}
\hline Ruas visitadas & $\begin{array}{c}\text { Espécies frutíferas comestíveis pelo homem } \\
\text { e pela fauna }\end{array}$ \\
\hline $\begin{array}{l}\text { Av. Anita Garibaldi } \\
\text { Bairro Barreirinha / Ahú }\end{array}$ & Cerejeira-do-japão (Prunus serrulata) \\
\hline $\begin{array}{l}\text { Rua Carlos Pioli } \\
\text { Bairro Bom Retiro }\end{array}$ & Cerejeira-do-japão (Prunus serrulata) \\
\hline Rua Luiz França & Guabirobeira (Campomanesia xanthocarpa) \\
Bairro Cajuru & \\
\hline Rua Romano Bertagnoli & Jerivá (Syagrus romanzoffiana) \\
Bairro Mercês & \\
\hline Calçadas do Bosque do Papa & Araçazeiro (Psidium cattleyanum) \\
Bairro Centro Cívico & Guabirobeira (Campomanesia xanthocarpa) \\
& Goiabeira (Psidium guajava) \\
& Pitangueira (Eugenia uniflora) \\
& Tarumã (Vitex montevidensis) \\
\hline
\end{tabular}

Através de um questionário estruturado foram entrevistados moradores de casas residenciais, das cinco ruas selecionadas. A seleção dos moradores entrevistados foi de maneira aleatória. Com a finalidade de obter o máximo de informações a respeito das árvores frutíferas e da ocorrência de fauna correlata foram selecionadas apenas residências. 
O conteúdo do questionário apresentou três questões referentes à arborização das ruas e três questões sobre a fauna associada (Quadro 1).

Quadro 1. Questionário aplicado aos moradores das ruas selecionadas.

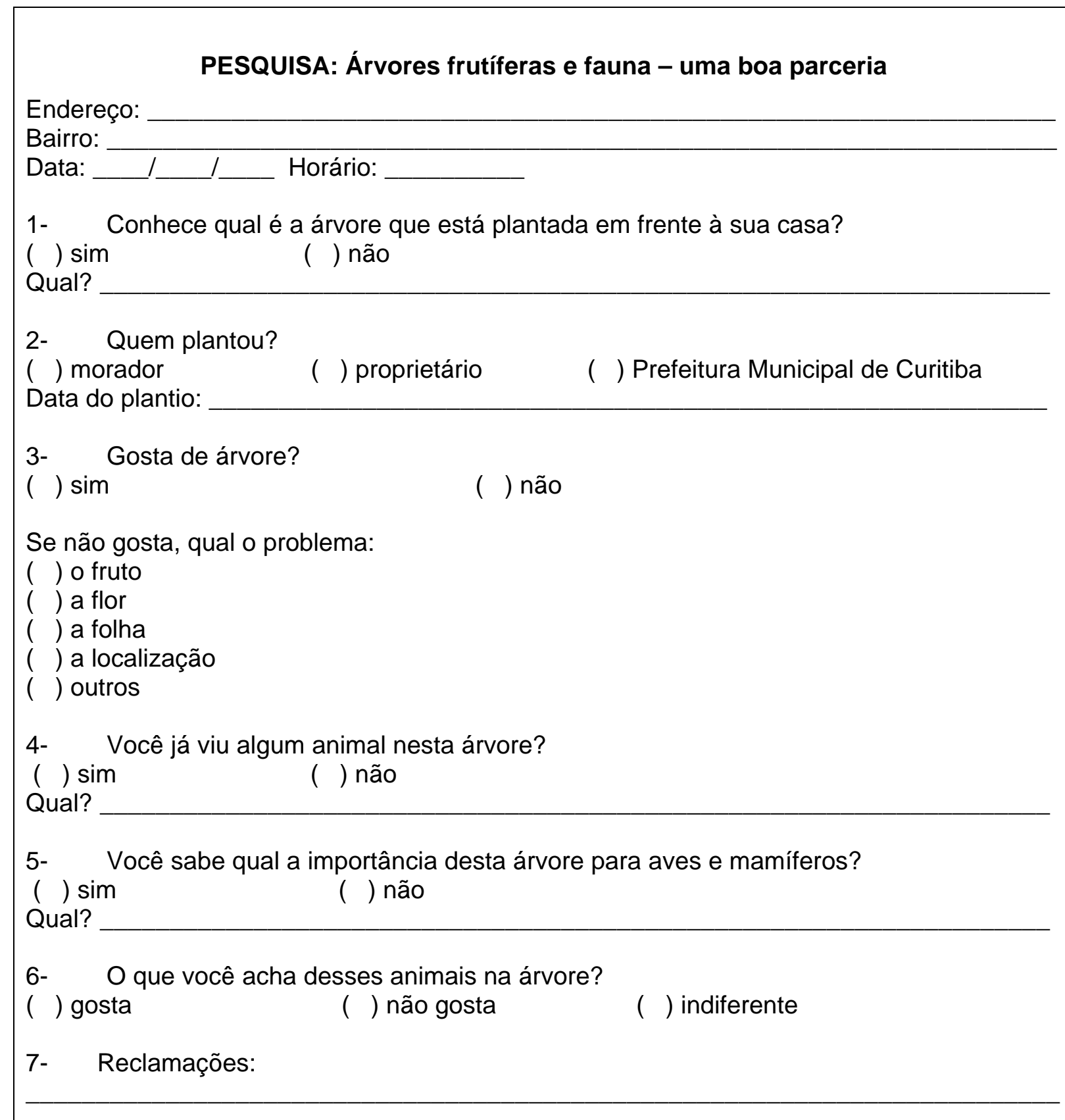

8- Sugestões:

Durante a aplicação do questionário foi entregue a cada casa visitada um folder contendo informações sobre as árvores frutíferas plantadas em Curitiba e a fauna correlata. 
O objetivo da elaboração desse material foi transmitir conhecimento sobre a importância do ecossistema urbano. No final dos questionamentos foi perguntado se o entrevistado teria alguma sugestão ou reclamação a fazer a respeito das árvores plantadas em frente a sua casa.

Os dados foram compilados em planilha Excel e tabulados em percentagem e gráficos.

\section{RESULTADOS E DISCUSSÃO}

Foram entrevistados 20 moradores nas ruas selecionadas na cidade de Curitiba. De todos os registros realizados, $85 \%$ deles revelaram que os moradores tinham conhecimento sobre a árvore plantada em frente de suas casas, sendo $55 \%$ delas plantadas pela Prefeitura Municipal de Curitiba, 30\% pelo proprietário ou inquilino e 15\% desconheciam quem plantou (Figura 2). A maioria dos moradores (85\%) indicou corretamente a espécie frutífera perguntada e, alguns souberam dizer a data em que elas foram plantadas. De maneira geral, esses resultados indicaram que os entrevistados parecem relacionar-se bem com a arborização viária, pois muitas vezes conhecem o histórico das árvores plantadas em frente às suas casas e acompanham o desenvolvimento das mesmas.

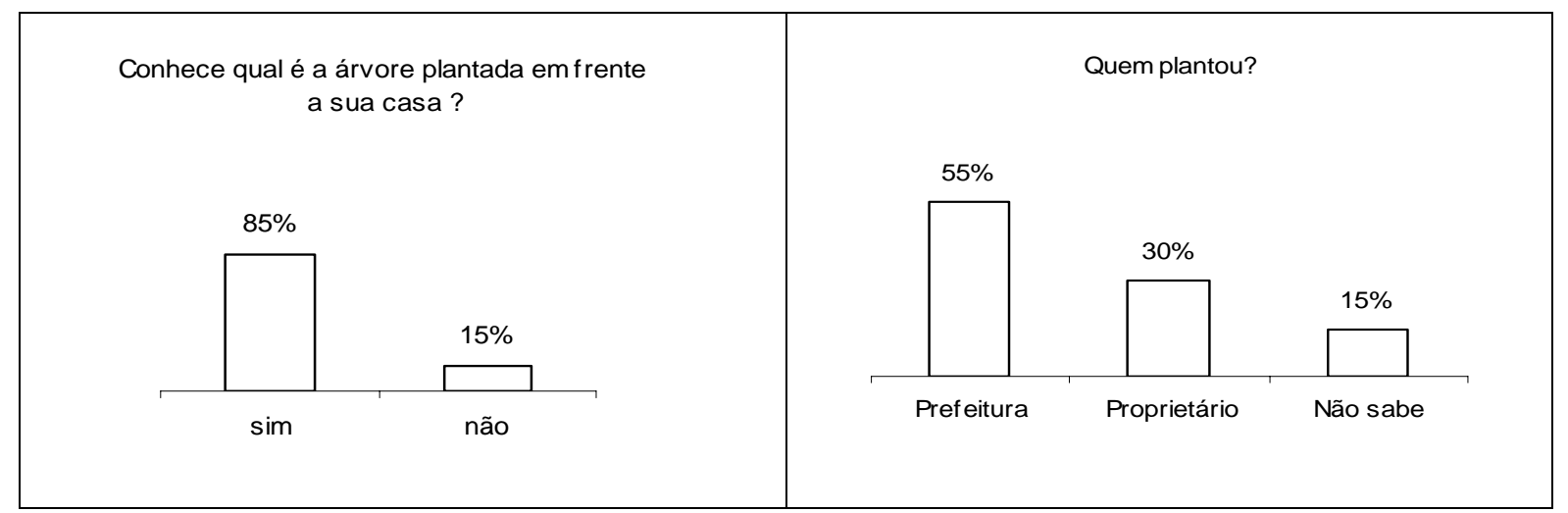

Figura 2. Respostas das questões referentes ao conhecimento do histórico das árvores frutíferas plantadas em frente às residências dos entrevistados.

Quanto à observação da fauna silvestre em ambiente urbano, 61\% dos entrevistados indicou já ter visto alguma ave na árvore em frente a sua casa, 13\% comentou ter visto morcegos, 4\% esquilo, 4\% gambá e 18\% não observaram animais (Figura 3). Os moradores demonstraram grande envolvimento com o meio em que vivem, pois a maioria relatou ter observado animais visitando flores e frutos das árvores frutíferas. Vários entrevistados 
falaram com grande entusiasmo das aves que aparecem não só nas árvores da rua como também nos quintais de suas casas.

Dos animais citados pelos moradores, as aves foram as mais freqüentes, provavelmente devido ao hábito diurno e a quantidade de indivíduos existentes. Pode ser também, devido ao número de espécies da avifauna ser maior que da mastofauna urbana, contribuindo para aumentar as chances de encontro e visualização pela população. Outro fator pode estar relacionado ao variado repertório de cantos e cores que encanta e transmite uma sensação de maior proximidade com a natureza e conseqüente bem-estar.

Dentre os mamíferos observados pelos entrevistados, os morcegos foram os mais citados. Os esquilos e os gambás também foram lembrados, porém com menor freqüência. Segundo Reis et al. (2006), morcegos são animais que apresentam hábito noturno e crepuscular, emitindo sinais que são audíveis pelo homem quando estão em deslocamento (ecolocalização). Os gambás também têm hábito noturno e crepuscular, porém, assim como os esquilos, são muito silenciosos e discretos sendo difícil sua percepção durante o período de atividade (LANGE e JABLONSKI, 1998; FERREIRA et al., 2007; PICCININI et al., 2007). Devido a essas características biológicas pode-se inferir que os moradores perceberam mais os morcegos por serem animais mais evidentes, facilitando sua percepção.

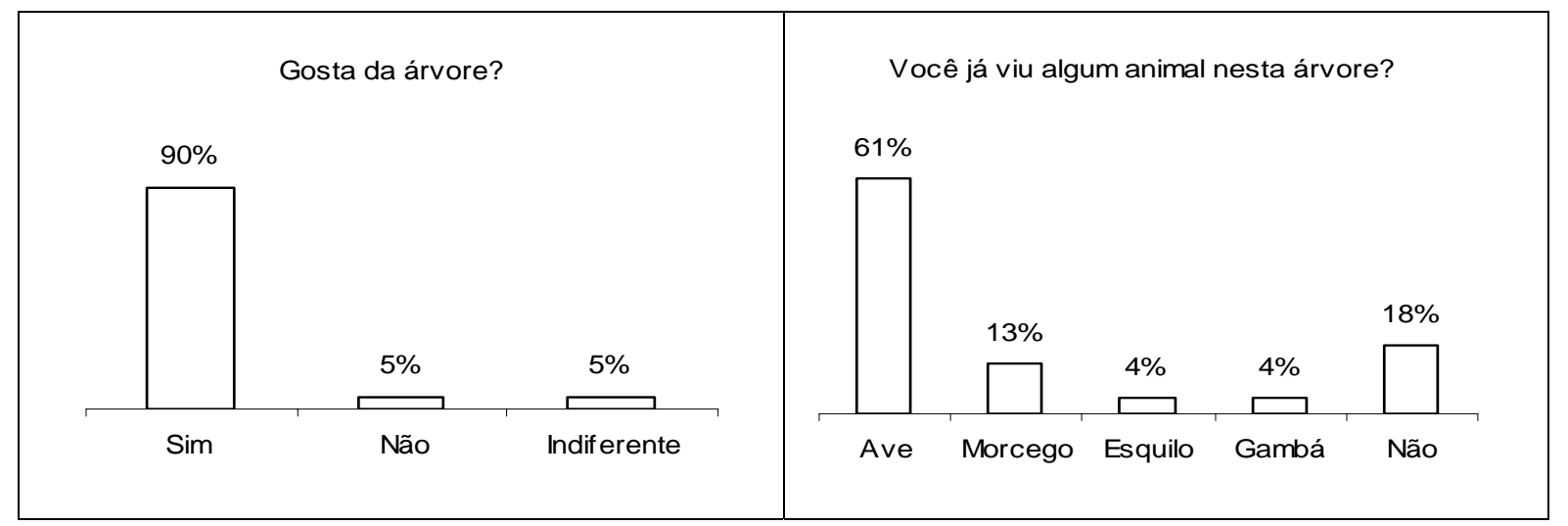

Figura 3. Respostas das questões referentes à percepção dos entrevistados em relação as árvores frutíferas e a fauna .

Quanto à percepção do ambiente urbano, constatou-se que 90\% dos entrevistados gostam das árvores frutíferas e dos animais associados a elas. Além disso, 90\% dos moradores têm consciência sobre a importância das mesmas para aves e mamíferos (Figuras 3 e 4). 


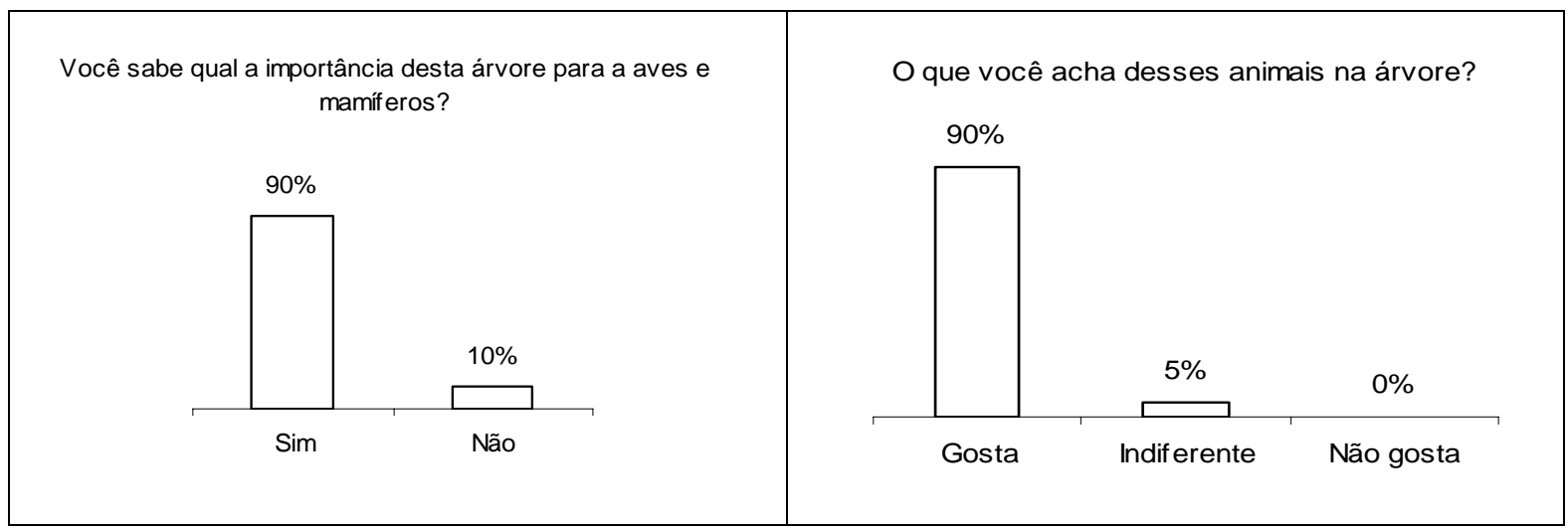

Figura 4. Respostas das questões referentes à fauna associada às árvores frutíferas.

É de conhecimento dos moradores entrevistados a relação da flora e fauna, pois a grande maioria concorda que as árvores viárias são importantes para as aves e mamíferos da cidade, no sentido de oferecerem alimento e abrigo. Alguns moradores mostraram também conhecer o funcionamento do ecossistema urbano quando comentaram sobre a importância dos animais como dispersores e a importância das árvores para o decréscimo da poluição.

Segundo Ferrara (1999), os estímulos do meio ambiente são sentidos pela mente mesmo sem se ter consciência disto. A mente humana organiza e representa a realidade percebida através de esquemas perceptivos e imagens mentais (VIGOTSKY, 1994). Evolutivamente o homem foi se distanciando do meio natural e, mesmo sem perceber, sente a necessidade do contato biológico com o meio. Talvez seja por essa razão que a grande maioria dos entrevistados gosta da presença dos animais na arborização das ruas ou no próprio quintal.

Entre as reclamações feitas pelos moradores, o vandalismo foi o mais expressivo (Figura 5). Segundo os moradores, essa atitude parece partir de jovens desocupados. Curitiba sofre com depredações desse tipo desde o século XX (OBA, 1998) e isso parece estar vinculado à cultura e percepção do meio ambiente de, pelo menos, parte da população. Atitudes como essas poderiam ser minimizadas com ações freqüentes e contínuas de educação ambiental, principalmente em escolas. 


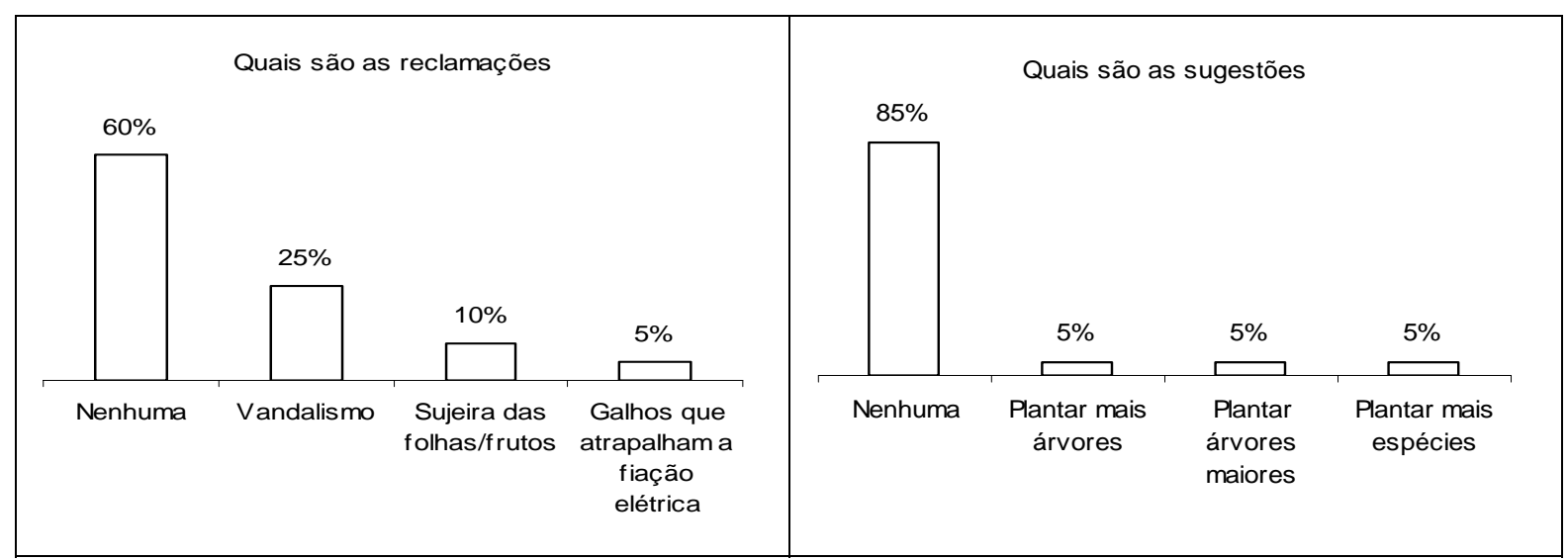

Figura 5. Respostas das questões referentes às reclamações e às sugestões feitas pelos entrevistados.

Durante a aplicação do questionário, os moradores citaram várias aves urbanas, as quais foram relacionadas ao hábito alimentar (Tabela 2). A alimentação das mesmas pode ser composta por vegetais (frutos, flores, sementes, brotos e folhas) e animais (artrópodes, crustáceos, moluscos, peixes, anfíbios, pequenas aves, répteis e ovos). Podem também comer restos de comida como é o caso do joão-de-barro e do pardal, demonstrando habilidade em adaptar-se ao convívio humano. 
Tabela 2. Relação das aves citadas pelos moradores entrevistados em Curitiba, 2008.

\begin{tabular}{|c|c|c|}
\hline Nome vulgar & Nome científico & Dieta alimentar * \\
\hline Anu-preto & Crotophaga ani & Insetos e larvas \\
\hline Bem-te-vi & Pitangus sulphuratus & $\begin{array}{l}\text { Artrópodes, pequenas aves, } \\
\text { ovos, peixes, crustáceos e } \\
\text { anfíbios. }\end{array}$ \\
\hline Canário & Sicalis sp. & Sementes \\
\hline Chopim & Molothrus bonariensis & Sementes e insetos \\
\hline João-de-barro & Furnariis rufus & $\begin{array}{l}\text { Insetos, larvas, artrópodes, } \\
\text { moluscos e restos de comida. }\end{array}$ \\
\hline Pardal & Passer domesticus & $\begin{array}{l}\text { Sementes, artrópodes, larvas e } \\
\text { resto de comida. }\end{array}$ \\
\hline Periquito & Brotogeris tirica & Frutos e sementes \\
\hline Pintassilgo & Carduelis magellanicus & Granívoro (sementes) \\
\hline Quero-quero & Vanellus chilensis & $\begin{array}{l}\text { Insetos, larvas, moluscos, } \\
\text { crustáceos e peixes. }\end{array}$ \\
\hline Rolinha & Columbina sp. & Frutos e sementes \\
\hline Sabiá-laranjeira & Turdus rufiventris & Onívoro (vegetal e animal) \\
\hline Sanhaço-cinzento & Thraupis sayaca & $\begin{array}{l}\text { Frutos, brotos, folhas, flores e } \\
\text { insetos. }\end{array}$ \\
\hline Suiriri & Tyrannus melancholicus & $\begin{array}{l}\text { Artrópodes, pequenos frutos e } \\
\text { sementes. }\end{array}$ \\
\hline Tiriva & Pyrrhura frontalis & Frutos e sementes \\
\hline
\end{tabular}

* Fonte dos dados de dieta alimentar: SICK (1988) e REINERT et al. (2004).

Espécies da avifauna brasileira têm se tornado comuns em ambientes modificados, sob o efeito das alterações antrópicas. Existem mais de 9000 espécies de aves no mundo, $21 \%$ delas são encontradas no Brasil (SICK, 1988) e 31\% destas estão representadas em ambiente urbano (MATARAZZO-NEUBERGER, 1995). 
As aves sejam elas insetívoras, frugívoras, granívoras, nectarívoras ou onívoras estão presentes no meio urbano, porque de alguma forma esse ambiente garante abrigo, alimento e água, requisitos básicos para a sobrevivência de qualquer espécie animal. $A$ arborização urbana favorece direta ou indiretamente a presença de invertebrados e vertebrados que atraem seus predadores ou dispersores formando a trama alimentar, garantindo o equilíbrio ecológico no ambiente urbano.

A arborização urbana com plantas frutíferas é praticamente inexistente nas cidades brasileiras, havendo poucos trabalhos realizados e publicados no mundo (MANICA, 1997). Segundo Andrade (2002), em 10\% dos bairros de Campos do Jordão-SP inventariados, apenas uma árvore frutífera foi encontrada. Em Piracicaba-SP o número de espécies que compõem a arborização do município é de 6,14\% (MICHI e COUTO, 1996) e em Sete de Setembro-RS, apresenta 12\% (COLETTO et al., 2008).

Planejar a arborização é fundamental para o desenvolvimento urbano. Considerando que a arborização é um fator determinante da salubridade ambiental, por ter influência direta sobre o bem estar do homem, é necessária a realização de um programa de arborização urbana que envolva a sociedade com órgãos públicos, dirigentes, universidades e escolas para que se atinjam resultados mais eficientes.

\section{CONCLUSÕES}

Com os resultados obtidos pode-se conferir que existe uma estreita relação entre os moradores entrevistados e as árvores frutíferas plantadas nas ruas.

A população das ruas amostradas, além de identificá-las, conhece seu histórico, acompanha seu desenvolvimento e se preocupa com o vandalismo das árvores em suas ruas.

Os moradores também se mostraram atentos aos animais presentes nas espécies frutíferas, demonstrando conhecer a relação das árvores com os animais para o equilíbrio do ecossistema urbano.

Principalmente devido à atenção da população com o ambiente urbano, conferida nesta pesquisa, sugere-se que o Poder Público Municipal, no planejamento da arborização urbana, avalie a possibilidade de utilizar mais espécies frutíferas (com consulta à população) para a alimentação e fixação da fauna no meio urbano, contribuindo para uma maior diversificação de espécies na cidade. 


\section{REFERÊNCIAS BIBLIOGRÁFICAS}

ANDRADE, T.O. Inventário e análise da arborização viária da estância turística de Campos do Jordão, SP. Piracicaba, 2002. 129f. Dissertação (Mestrado em Agronomia) Setor de Fitotecnia, Escola Superior de Agricultura Luiz de Queiroz, Universidade de São Paulo.

BIONDI, D.; ALTHAUS, M. Árvores de rua de Curitiba: cultivo e manejo. Curitiba: FUPEF, 2005. $177 \mathrm{p}$.

COLETTO, E.P.; MULLER, N.G.; WOLSKI, S.S. Diagnóstico da arborização das vias públicas do município de Sete de Setembro - RS. Revista da Sociedade Brasileira de Arborização Urbana, Piracicaba, v.3, n.2, p.110-122, 2008.

DANTAS, C.I.; SOUZA, C.M.C. Arborização urbana na cidade de Campina Grande - PB: Inventário e suas espécies. Revista de Biologia e Ciências da Terra, Campina Grande, v. 4, n. 2, 2004, n/p.

FERRARA, L.D.A. Olhar periférico: informação, linguagem, percepção ambiental. São Paulo: EDUSP, 1999. 227 p.

FERREIRA, M.S.; KAJIN, M.; VIEIRA, M.V.; CERQUEIRA, R.; D'ANDREA, P.S.; GENTILE, R. Análises de sensibilidade e elasticidade do marsupial Didelphis aurita (didelphimorphia, didelphidae) em mata atlântica: comparação entre área florestada e rural. In: Congresso de Ecologia do Brasil, VIII, 2007, Caxambu. Anais... Caxambu-MG, p 1-2, 2007.

FOLHA ON LINE (2004). Disponível em:

<http://www1.folha.uol.com.br/folha/turismo/noticias/ult338u4186.shtml>. Acesso em: 10/11/2008.

FRANCHIN, A.G.; OLIVEIRA, G.M.; MELO, C.; TOMÉ, E.R.; MARÇAL JUNIOR, O. Avifauna do campus Umuarama Universidade Federal de Uberlândia (Uberlândia, MG). Revista Brasileira de Zoociências, Juiz de Fora, v. 6, n. 2, p. 219-230, 2004. 
GERÊNCIA DE ARBORIZAÇÃO PÚBLICA. Informações fornecidas pela Gerência de Arborização Pública do Departamento de Produção Vegetal, Secretaria Municipal do Meio Ambiente, Prefeitura Municipal de Curitiba, Curitiba - PR, 08 maio 2006.

IBGE - Instituto Brasileiro de Geografia Estatística. População. Disponível em: < http://www.ibge.gov.br/home/estatistica/populacao/contagem2007/default.shtm>. Acesso em: $11 / 11 / 2008$.

IPPUC - Instituto de Pesquisa e Planejamento Urbano de Curitiba. Disponível em: http://www.ippuc.org.br. Acesso em: ago. 2006.

IPPUC. Curitiba em Dados 2004. CD-ROM. Curitiba-PR: Ippuc, 2004.

LANGE, R.B.; JABLONSKI, E. Mammalia do estado do Paraná, Marsupialia. Estudos de Biologia, Curitiba, v. 43, p. 15-224, 1998.

MAACK, R. Geografia física do estado do Paraná. Curitiba: Secretaria de Estado da Cultura e Esporte, 1981. 405 p.

MANICA, I. Fruticultura em áreas urbanas: arborização com plantas frutíferas, o pomar doméstico, fruticultura comercial. Porto Alegre: Cinco Continentes, 1997.154 p.

MATARAZZO-NEUBERGER, W.M. Comunidades de cinco parques e praças da Grande São Paulo, estado de São Paulo. Ararajuba, São Carlos, v. 3, p. 13-19, 1995.

MENDONÇA, L.B.; ANJOS, L. Beija-flores (aves, Trochilidae) e seus recursos florais em uma área urbana do Sul do Brasil. Revista Brasileira de Zoologia, Curitiba, v. 22, n. 1, p. 51-59, 2005.

MENDONÇA, L.B.; ANJOS, L. Feeding behavior of hummingbirds and perching birds on Erythrina speciosa Andrew (Fabaceae) flowers in an urban area, Londrina, Paraná, Brazil. Revista Brasileira de Zoologia, Curitiba, v. 23, n. 1, p. 42-49, 2006. 
MICHI, S.M.P.; COUTO, H.Z. Estudo de dois métodos de amostragem de árvores de rua na cidade de Piracicaba - SP. $1^{0}$ Curso em Treinamento sobre Poda em Espécies Arbóreas Florestais e de Arborização Urbana. Piracicaba. IPEF-USP. 1996. Disponível em: $<$ <ttp://www.ipef.br/publicacoes/curso_arborizacao_urbana/cap01.pdf>. Acesso em: $11 / 11 / 2008$.

MIRETZKI, M. Inventário de quirópteros de Curitiba (Paraná, Brasil). In: Congresso Brasileiro de Zoologia, XXI, 1996, Porto Alegre, Resumos, 1996.

OBA, L.T. Os marcos urbanos e a construção da cidade: a identidade de Curitiba. São Paulo, 1998. 184f. Tese (Doutorado em Estruturas Ambientais Urbanas). Faculdade de Arquitetura e Urbanismo, Universidade de São Paulo.

OLIVEIRA, M.M.A. Arborização e avifauna urbana em cidades do interior paulista. Boletim Centro de Estudos Ornitológicos, São Paulo, n. 7, p 10-14, 1990.

PICCININI, C.M.P.; SILVA, W.R.; SETZ, E.Z.F. A contribuição de Didelphis albiventris (Marsupialia, Didelphidae) para a dispersão de sementes em um fragmento florestal urbano. In: Congresso de Ecologia do Brasil, VIII, 2007, Caxambu. Anais... Caxambu-MG, p 1-2, 2007.

REINERT, B.L.; BORNSCHEIN, M.R.; BELMONTE-LOPES, R. Conhecendo as aves silvestres brasileiras. Londrina: GRAFMARKE. Cornélio Procópio: Grupo Ecológico Vida Verde de Cornélio Procópio, 2004. 163 p.

REIS, N.R. ; PERACCHI, A.L.; PEDRO, W.A. e LIMA, I.P. Mamíferos do Brasil. Londrina: Nélio R. dos Reis, 2006. 437p.

RODRIGUES, C.A.G.; BEZERRA, B.C.; ISHII, I.H.; CARDOSO, E.L.; SORIANO, B.M.A.; OLIVEIRA, H. Arborização urbana e produção de mudas de essências florestais nativas em Corumbá, MS. Corumbá: Embrapa Pantanal, 2002. 26 p.

ROPPA, C.; FALKENBERG, J.R.; STANGERLIN, D.M.; BRUN, F.G.K.; BRUN E.J.; LONGHI, S.J. Diagnóstico da percepção dos moradores sobre a arborização urbana na vila estação 
colônia - bairro Camobi, Santa Maria - RS. Revista da Sociedade Brasileira de Arborização Urbana, Piracicaba, v. 2, n. 2, p. 11-30, 2007.

SICK, H. Ornitologia brasileira, uma introdução. Brasília: Editora Universidade de Brasília, v. I e II, 1988. 827 p.

SPIRN, A.W. O jardim de granito. Tradução de Paulo Renato Mesquita Pellegrino. São Paulo: Universidade de São Paulo - Edusp, 1995. 345 p.

VIGOTSKY, I.S. A formação social da mente. São Paulo: Martins Fontes, 1994. $191 \mathrm{p}$. 